\begin{tabular}{|c|c|c|}
\hline$-\mathrm{T}$ & $\begin{array}{c}\text { European Association for the } \\
\text { Development of Renewable Energies, Environment } \\
\text { and Power Quality (EA4EPQ) }\end{array}$ & $\begin{array}{l}\text { International Conference on Renewable Energies and Power Quality } \\
\text { (ICREPQ'12) } \\
\text { Santiago de Compostela (Spain), 28th to 30th March, } 2012\end{array}$ \\
\hline
\end{tabular}

\title{
DFIG using its FACTS Features through the Grid Side Converter in Grid- Connected Wind Power Application
}

F. A. K. Lima ${ }^{1}$, D. V. P. Shimoda ${ }^{1}$, J. B. Almada ${ }^{1}$, M. I. B. V. Silva ${ }^{1}$, H. M. Oliveira Filho ${ }^{1}$ and J. L. Dantas ${ }^{2}$

\author{
${ }^{1}$ Department of Electrical Engineering \\ Federal University of Ceará \\ Campus of Pici - Fortaleza, 60455-900 Ceará (Brazil) \\ Phone/Fax number: +55 853366 9650, e-mail: klima@dee.ufc.br, dante@dee.ufc.br, janainaalmada@oi.com.br, \\ izabel.vieira@gmail.com, herminio@dee.ufc.br
}

\author{
${ }^{2}$ Federal Institute of Education, Science and Technology of Ceara - IFCE \\ Fortaleza Unit \\ P. Code 60040-531, Av. Treze de Maio, 2081, Benfica, Fortaleza - CE (Brazil) \\ Phone/Fax number: +55 853307 3607, e-mail: joacillo@ifce.edu.br
}

\begin{abstract}
This paper proposes a new control strategy to the grid side converter (GSC) of a DFIG-based wind turbine enabling the DFIG's FACTS features. This control strategy is based on the $p q$ Theory which take advantage of this converter to improve the energy quality at the point of common coupling (PCC) acting as an active filter in the specific case adopted in this article. The control strategy of the rotor side converter (RSC) adopted was the classical field-oriented control which determines the active and reactive power that will be injected in the electrical system. Simulation results in PSCAD/EMTDC and some discussions are also shown throughout the paper.
\end{abstract}

\section{Key words}

Wind Power Generation, DFIG, FACTS, pq Theory, Field-Oriented Control.

\section{Introduction}

Wind power is an economically competitive means of electricity and has experienced a tremendous growth during last decade [1]. The wind power systems are highly dependent on the wind. It is necessary to link them with the power grid for these systems can continuously provide electric power to customers, which is a big incentive for both customers and utilities companies.

Moreover it is very easy to connect a wind power resource to the grid [2]. The increasing capacity of the installed wind power generation facilities linked to the electrical network made it necessary to redesign the existing grid code (GC) requirements [3].

In this context the wind turbines based on Doubly-Fed Induction Generator (DFIG) are widely used and they are already responsible for a significant part of the global wind power. The stator of the DFIG is directly connected to the grid and a back-to-back converter is connected between the rotor and the grid as shown in Figure 1. The back-to-back converter is formed by the grid side converter (GSC) and the rotor side converter (RSC). The RSC can control the active and reactive power which flows from the stator [3].

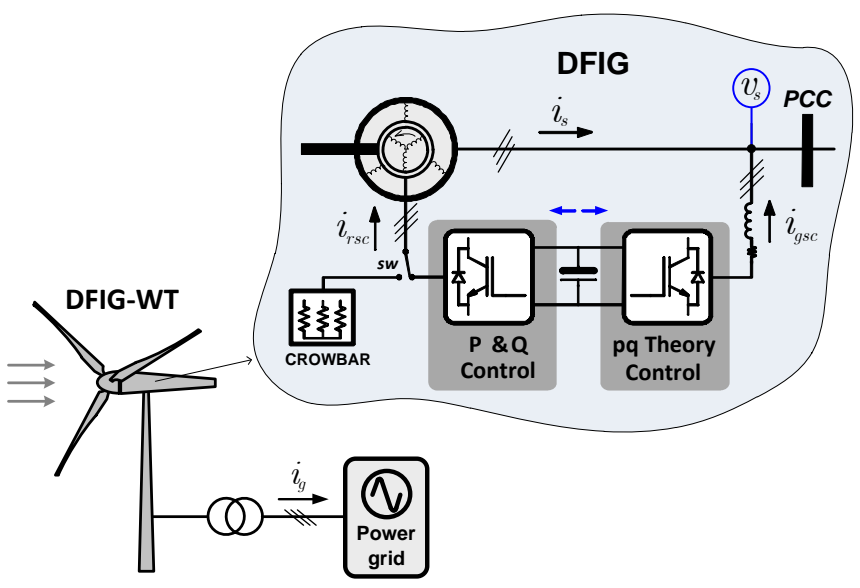

Fig. 1. DFIG Topology.

This work uses the classical control strategy for the DFIG RSC and it proposes a new control strategy for the GSC based on the $p q$ Theory. The aim of the proposed control strategy is to make the GSC to work as FACTS.

In addition, the control strategy based on $p q$ Theory require a lower computational effort and is more simple to implement than the classical control, because in the first case only one PI must be dimensioned unlike the second one which four PIs must be tuned in the same time.

It is very important to clarify that the control strategy for the GSC proposed here is not used to control active and 
reactive power as the standard control schemes using $d q$ components does. The concept shown aims take advantage of the GSC to make it works as FACTS giving the possibility to avail it to improve the energy quality of the grid in the point of common coupling (PCC).

According to the needs of the electrical system, the GSC may act as static synchronous compensator (STATCOM) or as active filter (AF). The control strategy was evaluated when the wind power system feeds a nonlinear load and under fault condition. The simulation software used in this study was PSCAD/EMTDC.

In the simulation presented in topic 3, the GSC works as $\mathrm{AF}$, compensating the current drained from the grid by a hard non-linear load (square load current), leaving the current injected in the grid with a sinusoidal shape.

In the case adopted in this article, the control strategy proposed needs to read the load currents. So this strategy with the AF characteristic should be utilized in Wind Turbines (WT) equipped with DFIG which is connected to the grid near to a specific known load.

In the case that this strategy has STATCOM characteristics, it should be used in WT that is connected to an electricity network that have a poor power factor and often poor voltage regulation. So the GSC could support the grid to promote the voltage stability.

\section{DFIG Model}

Assuming that DFIG stator has a low resistance, a low leakage inductance, a vector model with fast synchronization system and also considering that the magnetic circuit of DFIG is linear, it's possible to simplified the $5^{\text {th }}$ order model normally adopted [4].

The steady-state stator currents after the simplification in $d q$ synchronous reference frame are shown in (1) and (2) [3]-[4].

$$
\begin{gathered}
I_{s d}=\frac{1}{L_{s} \omega_{s}} V_{s q}-\frac{L_{m}}{L_{s}} I_{r d} \\
I_{s q}=-\frac{L_{m}}{L_{s}} I_{r q}
\end{gathered}
$$

Where:

$I_{s d, q}: \mathrm{d}$ - and q-axis stator current components.

$I_{r d, q}:$ d- and q-axis rotor current components.

$\boldsymbol{V}_{\boldsymbol{s q}}$ : Quadrature-axis stator voltage component.

$\omega_{s}$ : Angular frequency of the stator magnetic flux.

$L_{m}$ : Magnetizing inductance of the machine.

$L_{s}$ : Total inductance of the stator.

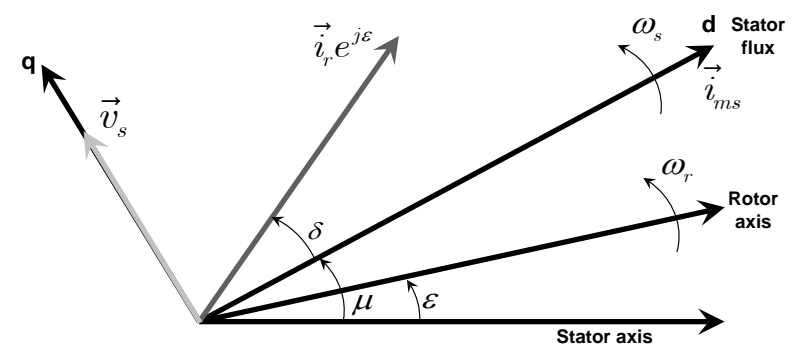

Fig. 2. Vector Diagram used in the RSC control system.

\section{A. The Rotor Side Converter}

The RSC controls the active and the reactive power inject or consumed by the DFIG. In this paper the rotor-side controller has been implemented considering a fieldoriented control (FOC) strategy in $d q$ reference frame. This reference frame is useful to reduce partially the complexity of the mathematical equation that describes this system [3].

Figure 2 shows the vector diagram in the $d q$ synchronous reference frame. Due to the low stator resistance the stator voltage $V_{S}$ can be considerate $90^{\circ}$ in advanced from stator magnetic flux $\left(\psi_{S}\right)$ on steady-state, and its direct component becomes zero $\left(V_{d s}=0\right)$. So the stator active and reactive powers can be written by (3) and (4).

$$
\begin{gathered}
P_{s}=-\frac{L_{m}}{L_{s}} V_{s q} I_{r q} \\
Q_{s}=-\frac{L_{m}}{L_{s}}\left(\frac{V_{s q}^{2}}{\omega_{s} L_{m}}-V_{s q} I_{r d}\right)
\end{gathered}
$$

Note that the quadrature-axis rotor current $\left(I_{r q}\right)$ can be to control the stator active power $\left(P_{S}\right)$, while the direct-axis rotor current $\left(I_{r d}\right)$ can be to control the stator reactive power $\left(Q_{S}\right)$.

Figure 3 shows the block diagram of the implemented control.

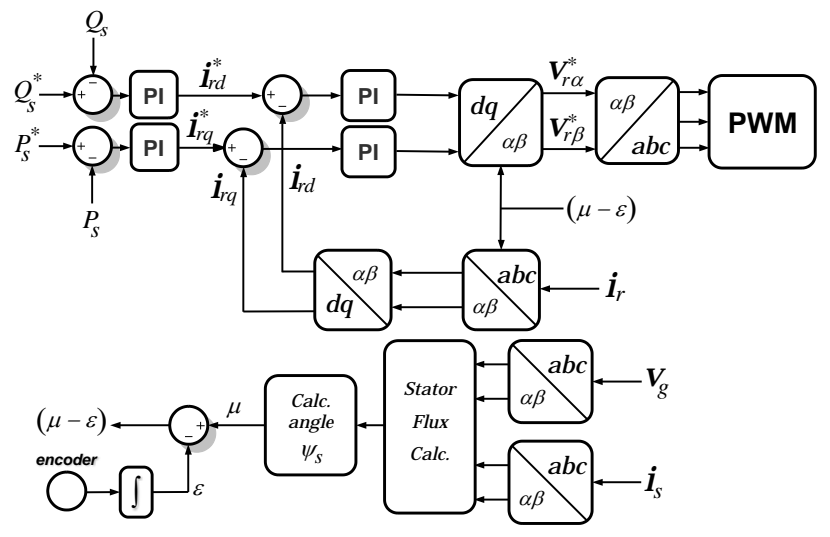

Fig. 3. RSC Control Strategy. 


\section{B. The Grid Side Converter as FACTS}

Power electronics systems offer new ways for controlling reactive power in both high-voltage transmissions and low-voltage distribution systems. Reactive power control allows voltage regulation for maintaining a stable operation of the power systems [5]. This section will be devoted to present a new control strategy applied to the GSC.

In the proposed grid side control based on the instantaneous active and reactive power theory ( $p q$ Theory), the grid side converter works as FACTS device. The operation mode of the GSC depends on the needs of the power system.

The $p q$ Theory is based on the $\alpha \beta 0$ transformation, also known as the Clarke Transformation, which consists in a real matrix to transform a three-phase voltages and currents into the $\alpha \beta 0$ stationary reference frame. The principal advantage of applying the $\alpha \beta 0$ transformation is the separation of zero-sequence components into the zero-sequence axis [6]. Naturally, the $\alpha$ - and $\beta$-axis do not have any contribution from zero-sequence components.

If the three-phase system has three wires (no neutral conductor), no zero-sequence current components are present and $\mathrm{i}_{0}$ can be eliminated in the above equations, simplifying them.

The present analysis will be focused on three-wire systems. Therefore, zero-sequence voltage or current is not present. In this situation the real and imaginary powers are given by (5).

$$
\left[\begin{array}{l}
p \\
q
\end{array}\right]=\sqrt{\frac{2}{3}} \cdot\left[\begin{array}{cc}
v_{\alpha} & v_{\beta} \\
v_{\beta} & -v_{\alpha}
\end{array}\right] \cdot\left[\begin{array}{c}
i_{\alpha} \\
i_{\beta}
\end{array}\right]
$$

Where $\mathrm{p}$ is the real power and represents the total energy flows per time unity in the three-wired three-phase system, in terms of $\alpha \beta$ components. $q$ is the imaginary instantaneous power and has a non-traditional physical meaning and gives the measure of the quantity of current or power which flows in each phase without transporting energy at any instant. It's important to explain p and q can be shown by two components each one when the load is nonlinear, as we could see in (6).

$$
\begin{aligned}
& p=\bar{p}+\tilde{p} \\
& q=\bar{q}+\tilde{q}
\end{aligned}
$$

Where $\bar{p}$ and $\bar{q}$ denote the average portion and $\tilde{p}$ and $\tilde{q}$ indicate the oscillating portion of $p$ and $q$, respectively. For balanced voltage sources, the oscillating powers $\tilde{p}$ and $\tilde{q}$ represent the undesirable powers due to harmonic components in the load current. In some situation $\bar{q}$ is an undesirable power as well.

This knowledge was used to control the GSC to work as FACTS, trying to stabilize the grid when occurs voltage sags and controlling the DC-link voltage of the back-toback converter. The strategy used to guarantee GSC to work as FACTS device is shown in the block diagram of Figure 4.

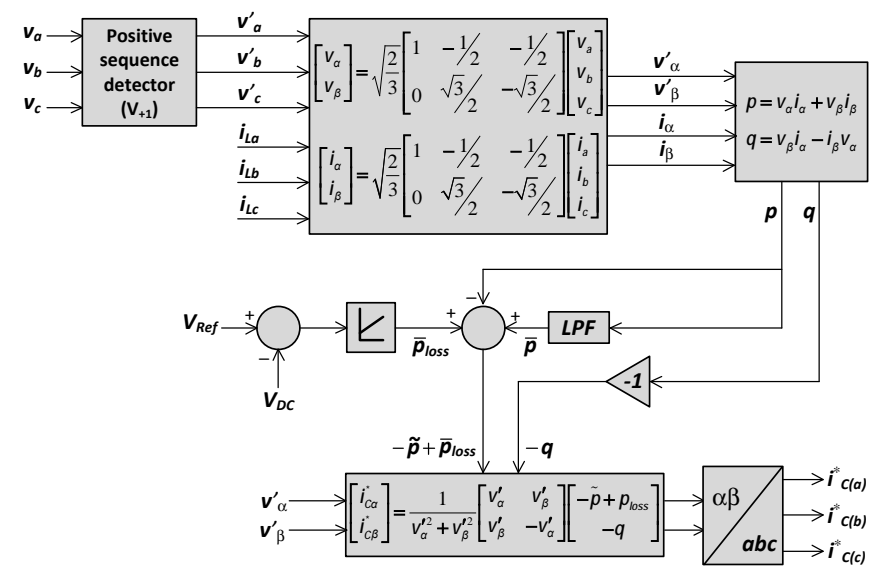

Fig. 4. Control strategy of GSC operating as FACTS device.

According to the control strategy shown in Figure 4, the active filter should compensate the oscillating real power and all imaginary power. Thus, the active power in PCC will be constant.

The compensated currents won't be sinusoidal if the voltage used in the control algorithm is not balanced and sinusoidal. This problem may happen if the voltage at the point of common coupling is distorted or unbalanced and used in the control algorithm. For this reason, in that work, it was used a positive sequence detector block. Thus, the voltage used in the block diagram in Figure 4 is perfectly balanced and sinusoidal.

Figure 5 shows the idea behind the active filtering performed in this paper. From the reading of the current drawn by a nonlinear load and the PCC voltage, the control system calculates the current compensation which must be synthesized by the active filter, in other words, by the grid side converter (GSC).

Based on this control strategy, the grid side converter controls the DC-link voltage, while it compensates the current drained by a nonlinear load, if it exists.

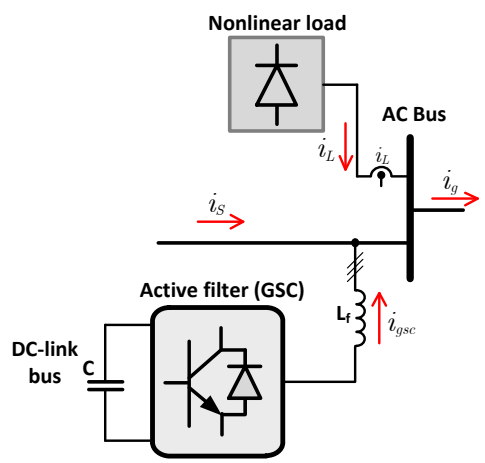

Fig. 5. Block diagram of active filtering.

In order to validate the control strategy proposed in this work, a computer simulation study will be performed. In the analyzed scenario the wind speed will be considered variable. The rotor side converter controls the stator active and reactive power independently, while the grid side converter will be tested using two control strategies. The first one uses the classical control strategy by the 
voltage-oriented control method. And the second one uses the control strategy proposed in this paper based on the $p q$ theory. Thus, the GSC will behave as an active filter for the last case. At the end, the two strategies are compared.

\section{Simulation Results}

The system was simulated for a strong grid with short circuit ratio (SCR) equal to 100 . At $t=2.0 \mathrm{~s}$, a $350 \mathrm{kVA}$ nonlinear load was connected to the AC bus. The wind turbine based on DFIG provides 1.0MW to the power. This study included variation in wind speed in order to make the simulation closer to a real case. Initially, it will be analyzed cases for the proposed control strategy.

Figure 6(a) shows that just at the moment of activation of the nonlinear load, the rotor speed suffers a small disturbance.

The active and reactive power generated from the wind turbine are shown in Figure 6(b). These powers are controlled by the rotor side converter. It is possible to note that the waveforms of the active and reactive power are in steady-state.

Figure 6(c) can be noted that occur a disturbance in the DC-link voltage at the time that the load was turned on.

From now on some comparisons between the classical and proposed control strategy will be performed.

Figures 6(d) and 6(e) shows the steady-state behavior of the stator and rotor currents in the phase 'a'. The currents behavior for the proposed strategy is depicted in Figure 6(d), whereas the Figure 6(e) shows the behavior for the classical solution. We can observe that both control strategies operate very similarly.

The performance of the injected current, load current and GSC current when both strategies are implemented can be compared thanks to the simulation plots depicted in Figure 7(a) and Figure 7(b), under exactly the same conditions.

The first plot shows the current behavior of the system during and after the connection of the nonlinear load to the grid. In this case the grid side converter of the DFIGWT implements the proposed control strategy, while in the second one the GSC implements the classical control strategy.

In the absence of nonlinear loads both strategies behave similarly. However, after the nonlinear load to be turned on becomes clear that the current injected into the power grid presents lower distortion in the first case, noticed in Figure 7(a).

Figures 7(c) and 7(d) shows details of the currents noticed in Figures 7(a) and 7(b), respectively. According to these figures is further obvious the effectiveness of control strategy based on $p q$ Theory, which can take advantage of the features of FACTS devices on the topology of wind turbines based on DFIG.

Finally, a comparison between the total harmonic distortions presented by currents injected into the grid for both control strategies is shown in Figure 8(a).

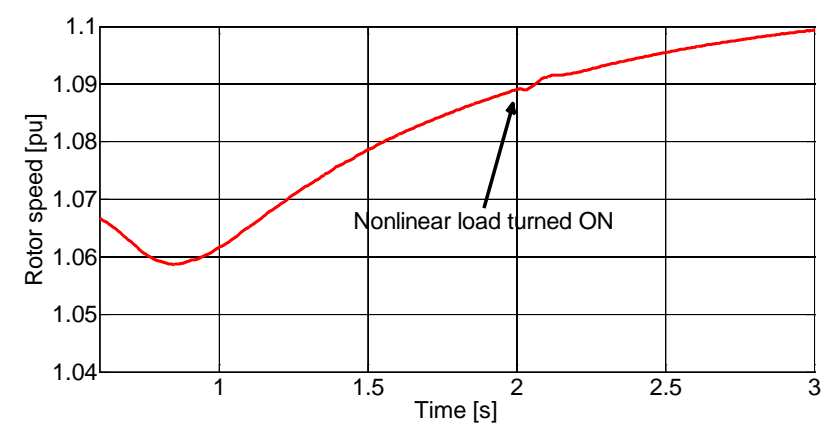

(a)

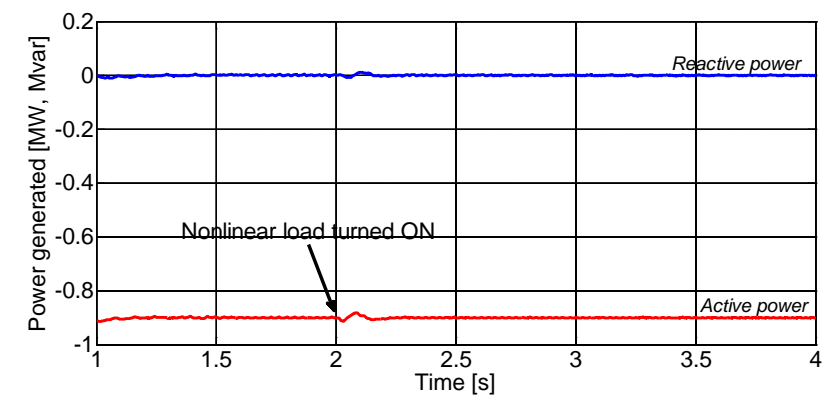

(b)

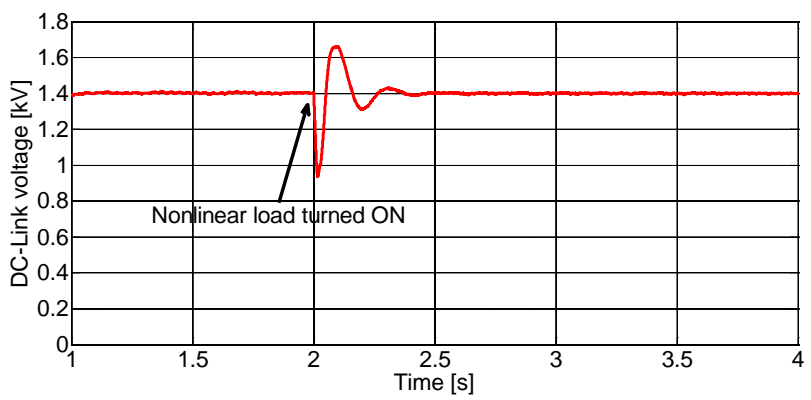

(c)

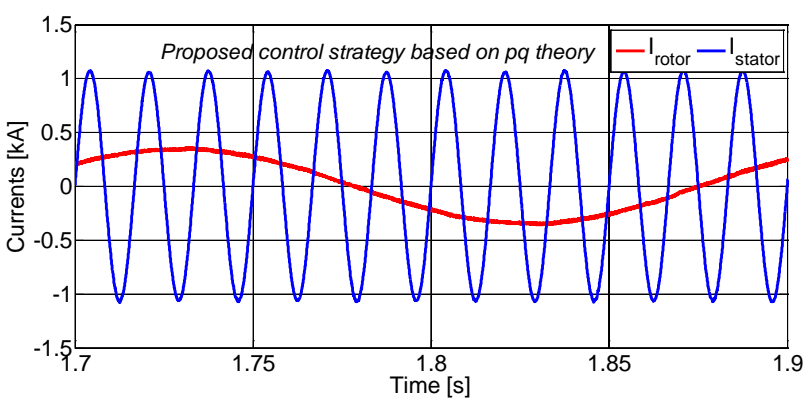

(d)

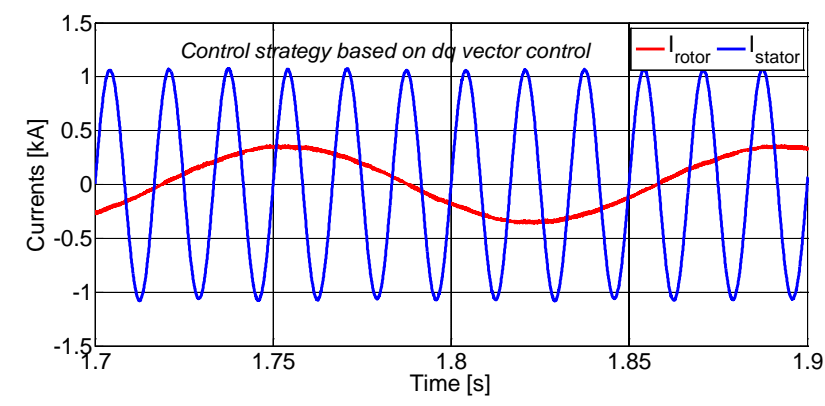

(e)

Fig. 6. (a) Rotor speed of the DFIG; (b) Active and reactive power at the AC Bus; (c) DC-Link voltage; (d) Stator and rotor currents ( $p q$ theory); (e) Stator and rotor currents ( $d q$ vector control). 


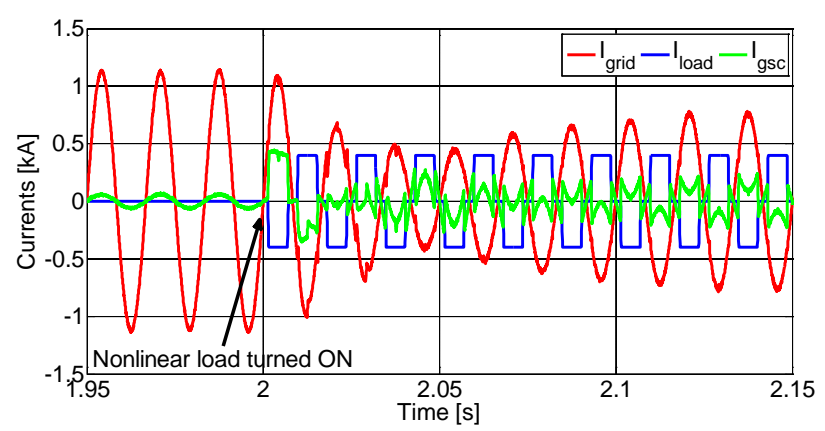

(a)

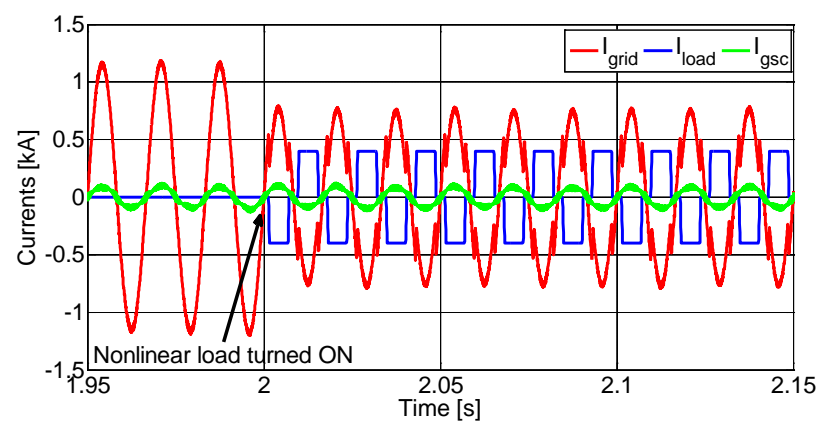

(b)

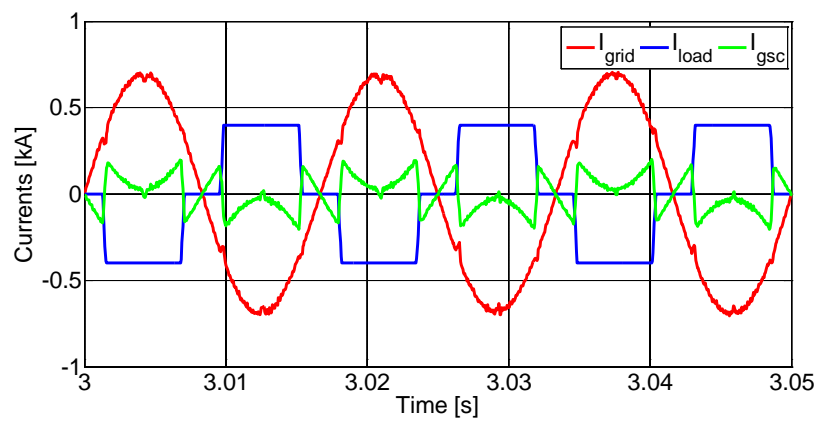

(c)

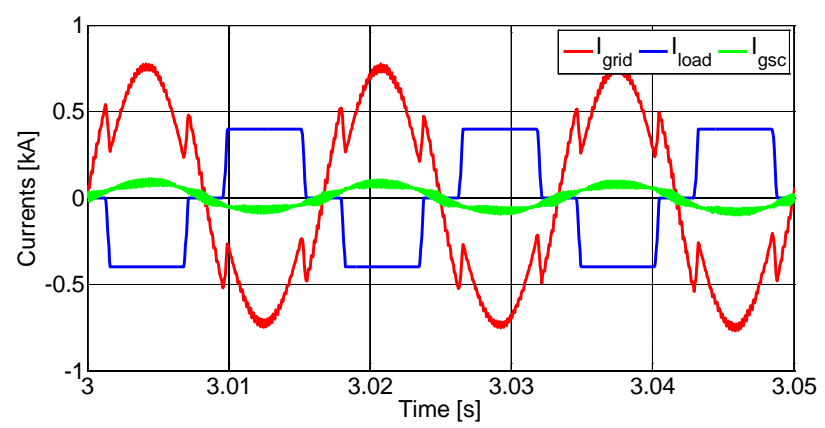

(d)

Fig. 7. (a) Currents from the proposed control strategy; (b) Currents from the classical control strategy; (c) Details of currents from the proposed control strategy; (d) Details of currents from the classical control strategy.

Before $t=2.0 \mathrm{~s}$ the injected currents synthesized by both control strategies presents practically the same THD. But, after this time, the classical control strategy shows more sensibility the presence of the nonlinear loads.

In this case, the THDi when used the classical control strategy presented value greater than $15 \%$. On the other hand, when was used the proposed control strategy this value remained lower than $3 \%$.

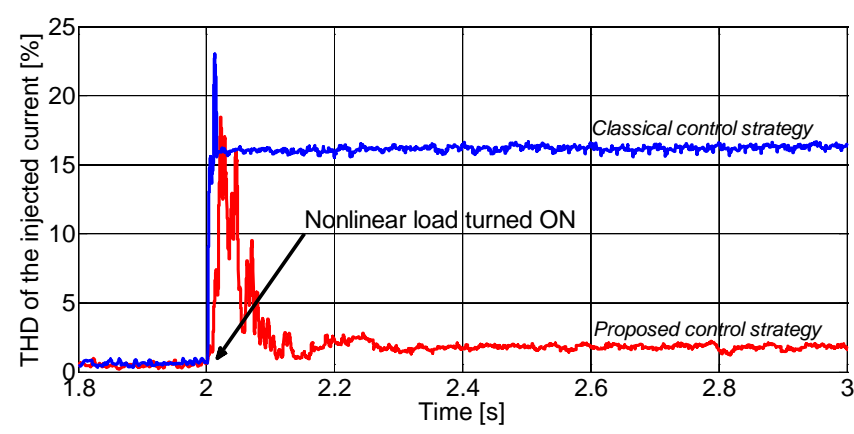

(a)

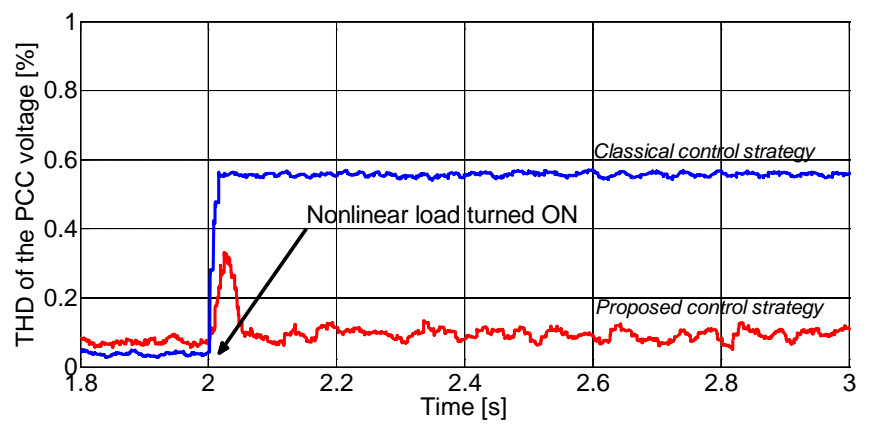

(b)

Fig. 8. (a) THD of the current injected into the grid; (b) THD of the PCC voltage.

Figure 8(b) shows the comparison between the total harmonic distortions presented by PCC voltage also for both control strategies.

Since the power grid considered in this study was strong, the immunity from the voltage to the nonlinear loads was guaranteed. However, the results indicate that in the case of a weak grid, the voltage at the PCC will be more sensitive when used the classical control strategy.

\section{Conclusion}

In this paper was presented a wind turbine based on DFIG and its mathematical modeling. It was proposed a control strategy for the grid side converter (GSC) based on the instantaneous active and reactive power theory. This control strategy allowed exploring the FACTS features from the GSC of the DFIG.

In order to show the robustness of the proposed control strategy a simulation was performed in PSCAD/EMTDC, in which a nonlinear load is connected to the system. Thus, this scenario was simulated using both the classical and proposed control strategy.

The simulation results showed that if there are no significant nonlinear loads connected to the system, both control strategies work properly and fairly similar. However, in the presence of significant nonlinear loads the proposed control strategy which compensates the current drained by the nonlinear load, seems to be more effective than the classic solution. As a consequence, the current injected into the power grid, for the last case, presents harmonic distortion less than when is used the classical control strategy. 
Summarizing, if there are no nonlinear loads connected to the point of common coupling the proposed strategy behaves similar to the classical control strategy (vector control in $d q$ synchronous reference frame). But, on the other hand, if there are loads with nonlinear features connected to the PCC the proposed strategy allows the compensation of the distorted currents giving more power quality at this point of the power system.

Thus, the control strategy proposed in this paper can be an interesting option for the grid-side converter control in DFIG-based wind turbines.

\section{Acknowledgement}

The authors acknowledge the support received from CNPq 554578/2010-7 for the development of the present work.

\section{References}

[1] S. Li, T.A. Haskew, S Mazari, "Integrating Electrical and Aerodynamic Characteristic for DFIG Speed Control Study”, Power Systems Conference and Exposition, pp. 1-8, 2009.

[2] E. S, Kim, B. M. Song, K. Y, Lee, "Modeling and Analyses of a Grid-Connected Wind Energy Conversion System Using PSCAD/EMTDC,” Innovative Smart Grid Technologies (ISGT), pp. 1-6, mar. 2010.

[3] F. A. K. Lima, A. Luna, P. Rodriguez, E. H. Watanabe, "Rotor Voltage Dynamics in the Doubly-Fed Induction Generator during Grid Faults,” IEEE Transaction On Power Electronics, Vol. 25, pp. 118-130, 2010.

[4] A. Luna, F. A. K. Lima, D. Santos, P. Rodriguez, E. H. Watanabe, S. Arnaltes, "Simplified Modeling of a DFIG for Transient Studies in Wind Power Applications", IEEE Transaction On Industrial Electronics, Vol. 58, pp. 9-20, 2011.

[5] P. Rodriguez, A. Luna, G. Medeiros, R. Tedorescu, F. Blaabjerg, "Control of STATCOM in Wind Power Plants based on Induction Generators during Asymmetrical Grid Fault”, Power Eletronics Coference (IPEC), pp. 2066-2073, 2010.

[6] H. Akagi, E. H. Watanabe, M. Aredes, "Instantaneous Power Theory and Applications to Power Conditioning", Willey-IEEE Press, 2007. 